\title{
The Important Leadership Competencies Of Higher Echelon To Middle-Level Managers In Thailand
}

Niruemol Maneesawangwong, Ramkhamhaeng University, Thailand Auychai Suvanujasiri, Ramkhamhaeng University, Thailand

\begin{abstract}
This research investigation lays a foundation for extending research in the area of the Leadership Competencies. This study provides a different perspective in viewing Leadership Competencies, inasmuch as it shows the important leadership competencies, examine the relationships between these important leadership competencies and the demographical characteristics of participants and explore ways to develop an efficacious approach to develop the important leadership competencies. This research paper was based on the 1998 leadership competency model developed by Eyde et al. (1999) and latest version of The Leadership Competency Model by U.S. Office of Personal Management (OPM). Thus, it can be said that this study provides excellent guidance to human resource managers, teachers, other educators, researchers and business management in the search for tools useful to the task of building a prosperous firm and organization in the current global business environment.
\end{abstract}

Keywords: Management; Competency; Leadership; Thailand; Human Resource

\section{INTRODUCTION}

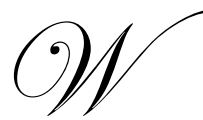

orld economic integration is proceeding apace and national economies are accordingly becoming more and more interdependent. The economic integration of the Kingdom of Thailand (Thailand) into the world economy is an important feature of the 11th National Economics and Social

Development Plan. The Association of Southeast Asian Nations (ASEAN) has developed an intra-ASEAN free trade policy, which has been extended to encompass the People's Republic of China (PRC), Japan, and the Republic of India (India). As part of the program for the ASEAN Community project, tariffs will be reduced in 2015 in line with the ASEAN Free Trade Area (AFTA) agreement. As such, operative in ASEAN is a new spirit of cooperation as witnessed by cooperation in investment and the transnational liberalization of service sectors. If Thai workers evince levels of skill and competency meeting higher standards, than these workers will have greater latitude and mobility in pursuing employment opportunities. For such eventualities, the country must be prepared in many ways, particularly in the area of human resources development. To compete with other ASEAN countries, the fullest feasible development of human capital must become a priority. The development of competencies is of paramount importance at the higher echelon and middle management levels. In this case, competencies must be developed in various countries and the capacity to understand diverse cultures, entrepreneurship, strategic thinking, etc. The key factor to heighten the country's competitiveness is to adopt human resources development policies hinging on the fostering of high-level skills and knowledge-based capacities.

This paper studies most of the important leadership competencies applicable to the higher-echelon to the middle manager levels and explores the most effective means of developing leadership competency in Thailand. The results of this study could prove very useful for higher-echelon, managers, human resource, teachers, other educators and researchers. It is important to determine what leadership competencies are important for higher echelon to middle level managers in Thailand and how to foster these competencies through the development of appropriate programs. 


\section{LITERATURE REVIEW}

The concept of "competency-based human resources" was introduced by McClelland (1973) in his article 'Testing for Competence rather than for Intelligence." Boyatzis (2008) indicated that an individual's maximum performance will occur in a situation in which individual capacity is confronted with job demands within a particular organizational environment. Individual performance and talent draws on vision, values, philosophy, knowledge, competencies and abilities, life/career stages, style and interests. Job demands involve tasks, functions, and roles. The organizational environment includes the factors of culture and climate, structure and systems, maturity of the industry and strategic position of the organization vis-à-vis core competences

Vathanophas and Thai-ngam (2007) have identified required competencies and have developed a competency model for effective job performance at the Chief of the General Administrative Sub-Division position level in the Thai Department of Agriculture. The researcher analyzed this model by means of an extrapolation of the behavioral event interview (BEI) technique (Spencer and Spencer, 1993). In this study, it was found that twenty-three competencies were required for those holding this position. These competencies are as follows: "developing others," "organizational awareness," "achievement orientation," "professional expertise," "self-improvement," "team leadership," "directiveness," "interpersonal understanding," "relationship building and coordination," "organizational commitment," "initiative," "flexibility," "self-confidence," "communication and influence," "information technology and computer literacy," "service-minded," "analytical thinking," "integrity," "concern for order, quality and accuracy," "information seeking," "self-control," "conceptual thinking," and "English skills."

Ling, Chia, and Fang (2000) have tested a competency model in the PRC. They found that interpersonal, goal efficiency, personal morality, and versatility factors are the most important components of the competency model tested. Their model is most appropriate in a collectivist culture, as in the PRC, with greater emphasis placed on performance by reference to group outcomes instead of individual outcomes.

Hayes (2007) reviewed a case study in which evaluated was leadership development at the Manitoba Lotteries Corporation. This case study was concerned with various dimensions in a leadership program for 258 supervisors and managers to the end of isolating discrete leadership competencies. The leadership dimensions consisted of eleven competency areas as follows: Team work and cooperation, building strategic performance, self-development and initiative, achieving quality results, coaching and developing competency, communication, valuing diversity, customer service, integrity and building trust, technical/professional knowledge and leading. This paper reviewed the evaluation process and subsequently the competency development program itself. The author concluded that there were three factorial dimensions leading to a successful leadership program. The first factorial dimension is having conducted a comprehensive needs assessment and clearly identifying participant needs. The second factorial dimension is a strong evaluation process and insuring continuing commitment to learning. The last factorial dimension is the obtaining of strong support from the executive management.

Qiao and Wang (2008) explore the competencies of middle-level managers in the PRC using both quantitative and qualitative methods. In their first study, the authors identify critical competencies for middle-level managers by applying an earlier leadership competency model developed in 1998 (Eyde et al., 1999). This model included a set of twenty-seven competencies. Focus groups, interviews, and survey questionnaires were used in the second study with two companies participating. On the basis of the first study, the authors concluded that accountability, team building, management of relationships, continual learning and conflict management are the most important competencies. In respect to the second study, the authors found that team building, communication, coordination, problem solving and execution were the most important competencies for the first company and team building, communication, continual learning, execution and technical expertise were the most important competencies for the second company.

Jackson and Humble (1994) concluded that the most important roles of middle-level managers are as follows:

1. Middle-level manager need to convert company strategies into operational activities and determine that overall direction fits the real situation.

2. Middle-level manager need to be role models for their subordinates.

3. Middle-level managers are the source of "know-how" in their companies. 
The authors contend that a number of factors affect the role of the middle-level manger, including the information technology (IT) revolution, creativity, values and beliefs. Finally, the authors suggest that the middle-level manager should become a new breed of manager, which, as such, involve involving five aspects: culture and values, organizational structure, information, motivation and direction.

\section{RESEARCH QUESTIONS}

This research investigation has three objectives. The first objective is to study the important leadership competencies of the higher echelon to middle-level managers in Thailand by reference to empirical investigations carried out by MBA students at Ramkhamhaeng University in Bangkok and its environs. The second objective is to examine the relationships between the important leadership competencies and the demographical factors of age, gender, highest position held, as well as size, ownership and type of business organization. The last objective is to study and explore ways to develop an efficacious approach whereby higher echelon to middle-level managers can acquire these important leadership competencies. The following research questions address these objectives in the following terms:

Question 1: What are the important leadership competencies for the higher echelon to middle-level managers in Thailand?

Question 2: What is the relationship between these leadership competencies and the demographical characteristics of the participants (age, gender, highest position held, size of business organization, ownership of business organization, and size and type of business organization) in Thailand?

Question 3: What activities would be efficacious in developing leadership competencies in higher echelon to middle-level managers in Thailand?

\section{CONCEPTUAL MODEL}

The leadership competency model was originally developed by the government of the Unites States and has been widely used in the USA and other countries as an instrument of investigation and evaluation. Nevertheless, hitherto research has been inadequate in respect to higher echelon to middle-level management leadership competencies, especially in Thailand. Therefore, in the view of the researcher, the results of this study should prove very useful to those at higher echelon to executive managerial levels, teachers, other educators, and researchers. It is important to explore what leadership competencies are important for higher echelon to middle-level managers in Thailand and how to approach those competencies when planning development programs.

Competency is a factor in increasing competitiveness between organizations, especially in respect to the ability to manage human resources. Various organizations accordingly strive to implement competencies in its leaders using such tools as human resource management and curriculum development. The U.S. Office of Personal Management (OPM) has released the latest version of The Leadership Competency Model that can be downloaded from the following website: 〈http://apps.opm.gov/ADT/Content.aspx?page=RelatedDocumentsandJScript=1>

The latest competency model incorporates twenty-eight competencies. These competencies are grouped into six clusters. The first group is labeled "leading change" under the rubric of which fall the six competencies of vision, external awareness, creativity and innovation, strategic thinking, resilience, and flexibility. The second group called "business acumen" has three competencies falling under its rubric: financial management, human resource management and technology management. The third group is categorized under the rubric of "results-driven" with six competencies falling under its rubric: accountability, problem solving, decisiveness, customer service, entrepreneurship and technical credibility. The fourth group is designated as "building coalitions" under whose rubric fall the three competencies of partnering, political savvy, and influencing/negotiating. The fifth group is specified as "fundamental competencies" with the six competencies of interpersonal skills, oral communication, integrity/honesty, written communication, continual learning and public service motivation. The last group is referred to as "leading people" under whose rubric fall four competencies: conflict management, leveraging diversity, developing others and team building.

In developing a leadership competency model in the PRC, Wang (2006) adapted the leadership competency model so as to be suitable to the cultural and social environment to which the model was to be applied. In this study, the researcher will follow Wang's adapted model with the proviso that additional leadership competencies will be added that 
better fit the cultural and social environment in Thailand. Added are the leadership competencies of operations management, English language skills, Mandarin language skills, follow-up, gathering and analyzing data, and technology management. Most of these competencies were based on a review and selected from the list of leadership competencies provided by The New York State Department of Civil Service/Governor's Office of Employee Relations, Work Force and Succession Planning (<www.cs.state.ny.us $\rangle)$.

\section{METHODOLOGY AND DATA COLLECTION}

In carrying out this research inquiry, Ramkhamhaeng University graduate students in business administration were recruited to participate in this survey investigation. A total of 400 male and female students enrolled in the graduate business administration programs were recruited. The reason for selecting MBA students for participation in this study was that the majority of them currently are higher echelon to middle-level managers so forth they have extensive understanding of higher echelon to middle-level management.

The researcher used a quadripartite questionnaire in this investigation as described in the following terms: (1) questions eliciting demographical data; (2) gathering data pertaining to leadership competencies; (3) amassing data relevant to the most critical leadership competencies of higher echelon to middle-level managers; and (4) collecting data relevant to the efficaciousness of activities that are germane to developing the leadership competencies of higher echelon to middle-level managers.

Prior to addressing the first research question, the researcher used techniques of descriptive statistics to analyze the aforementioned demographical characteristics of the participants. The demographical data were subsequently analyzed through applying techniques of descriptive statistics and tabulated in terms of frequency and percentage. In order to address the first research question, mean values and standard deviations at a confidence interval of 95 percent were calculated. Moreover, the five most critical leadership competencies for higher echelon and middle-level managers were examined and compared.

To test the second research question, multiple regression analysis was applied by means of using the stepwise method to examine the relationships between leadership competencies and the aforementioned demographic data. Some of the independent variables were nominal variables and dummy coding was accordingly used.

In examining the third question, mean value and standard deviation at the 95 percent confidence interval were calculated in answering the question concerning efficacious approaches for helping higher echelon to middlelevel managers acquire these important leadership competencies.

This study is designed to answer these questions from both academic and practitioner viewpoints. Emphasized is developing a leadership competency model for successful higher echelon to middle-level managers in Thailand.

\section{RESULTS}

To address the first research question, mean values and standard deviation at 95 percent confidence intervals were computed for purposes of ascertaining the levels of importance of leadership competencies for upper echelon and middle-level managers in Thailand.

Table 1: Comparison of the Important Leadership Competencies Using Two Methods, Viz., the Mean Ranking Method and Determining the Five most Important Competencies

\begin{tabular}{|l|l|}
\hline Mean Ranking Method & Five Most Important Competencies Method \\
\hline Honesty and integrity & Vision \\
\hline Accountability & Strategic thinking \\
\hline Team building & Honesty and integrity \\
\hline Customer service & Operational management \\
\hline Continual learning & Team building \\
\hline
\end{tabular}


Table 1 shows that the first to the fifth ranked item on the basis of applying the mean ranking method were honesty and integrity, accountability, team building, customer service and continual learning. The first to fifth rankings on the basis of applying the five most important competencies method were vision, strategic thinking, honesty and integrity, operational management and team building. There are two competencies that overlap when the two methods are applied seriatim. These competencies are honesty and integrity and team building.

Research Question 2: What is the relationship between these leadership competencies and the demographical characteristics of the participants (age, gender, highest position held, size of organization, ownership of organization and size and type of business organization) in Thailand?

On the basis of the results presented in Table 2, the following conclusions were drawn:

1. Older participants tended to evince higher levels of perception of the importance of vision and external awareness, but tended to exhibit lower levels of perception of the importance of English and Mandarin language skills.

2. Participants who held staff up to supervisorial positions tended to display higher levels of perception of the importance of political savvy, but tended to evince lower levels of perception of the importance of honesty and integrity and team building.

3. Participants who held middle-manager positions tended to exhibit lower levels of perception of the importance of external awareness and Mandarin language skills.

4. Participants who held executive-manager positions tended to display higher levels of perception of the importance of gathering and analyzing data.

5. Participants who worked in small organizations (1-100 employees) tended to manifest lower levels of perception of the importance of political savvy and building coalitions/communications.

6. Participants who worked in medium-sized organizations (101-500 employees) tended to evince lower levels of perception of the importance of entrepreneurship and service motivation.

7. Participants who worked in large organizations (more than 501 employees) tended to exhibit higher level perceptions of the importance of gathering and analyzing data.

8. Participants who worked in government/non-profit organizations tended to display lower levels of perception of the importance of external awareness, strategic thinking, entrepreneurship, organizational structure and cultural knowledge, leading change and building coalitions/communications.

9. Participants who worked in private organization tended to manifest lower levels of perceptions of the importance of political savvy and building coalitions/communications.

10. Participants who were owners of businesses tended to evince higher levels of perception of the importance of political savvy, financial management, customer service, Mandarin language skills, follow-up and business acumen.

11. Participants who worked in the service business tended to display lower levels of perception of the importance of strategic thinking, organizational structure and cultural knowledge and continual learning.

12. Participants who worked in multinational organization tended to exhibit lower levels of perception of the importance of strategic thinking, but tended to evince higher levels of perception of the importance of management relationship.

13. Participants who worked in state-owned enterprises tended to manifest higher levels of perception of the importance of management, customer service and business acumen. 
Table 2: Results of Hypothesis Testing Using Regression Analysis (stepwise method)

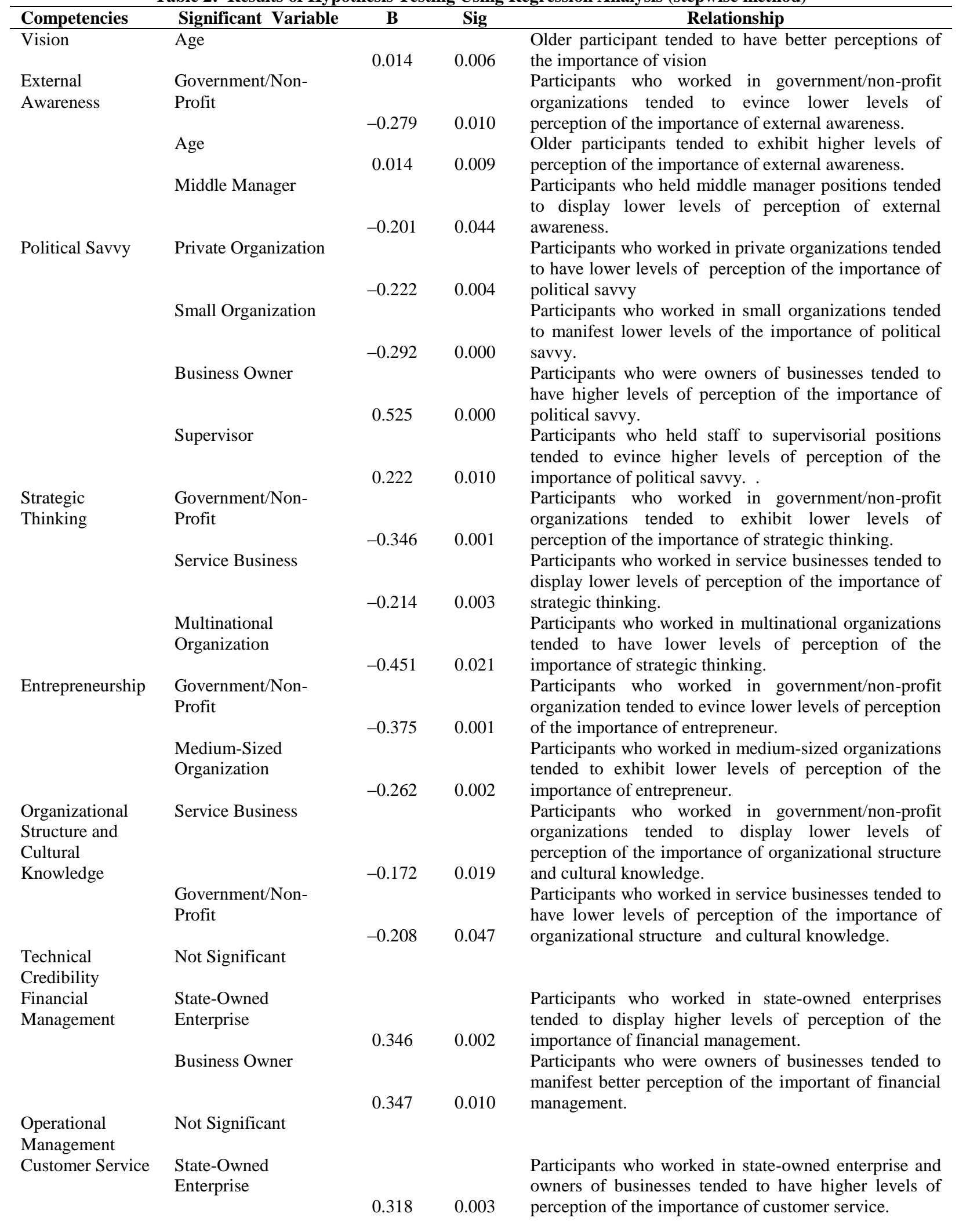


Table 2: continued

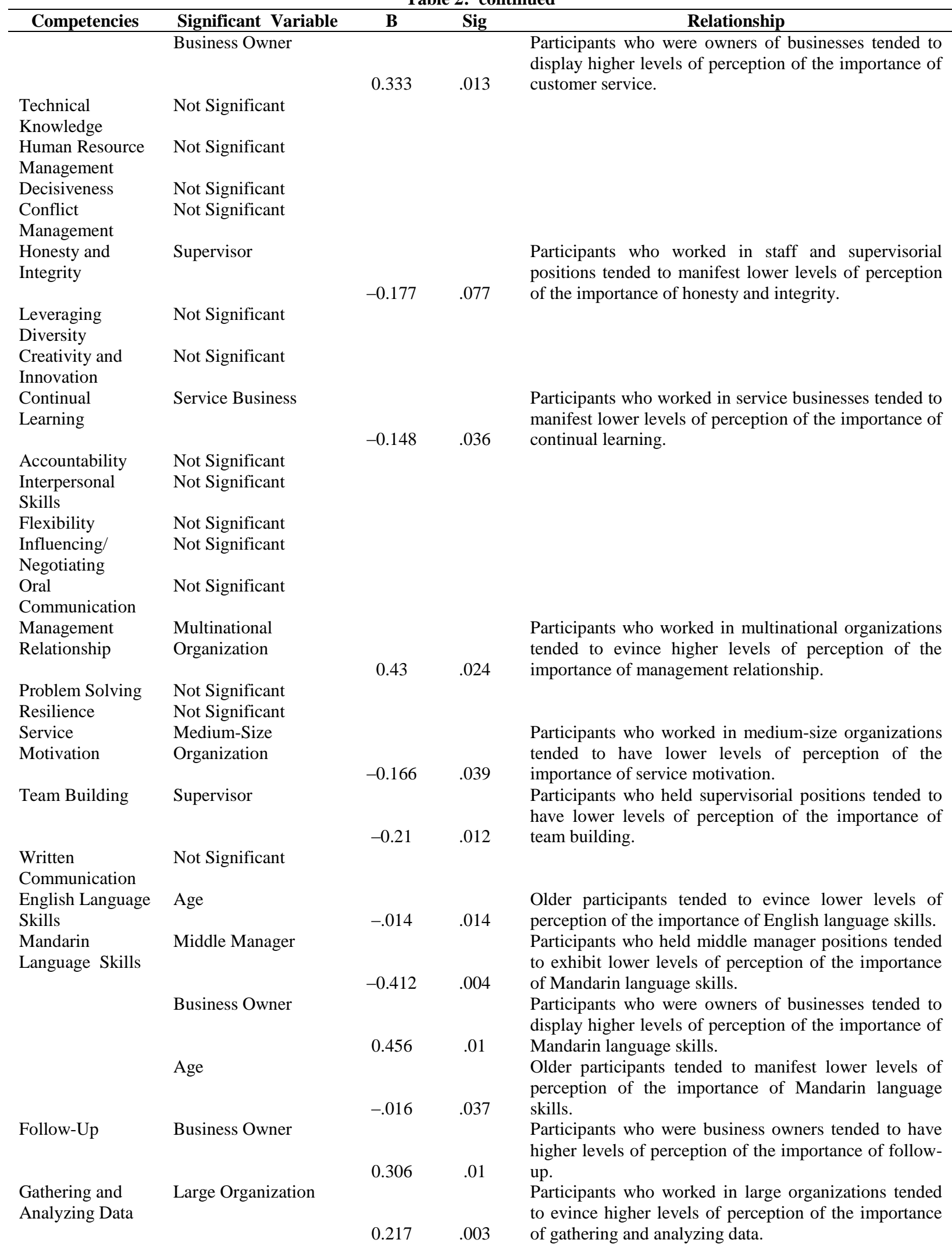


Table 2: continued

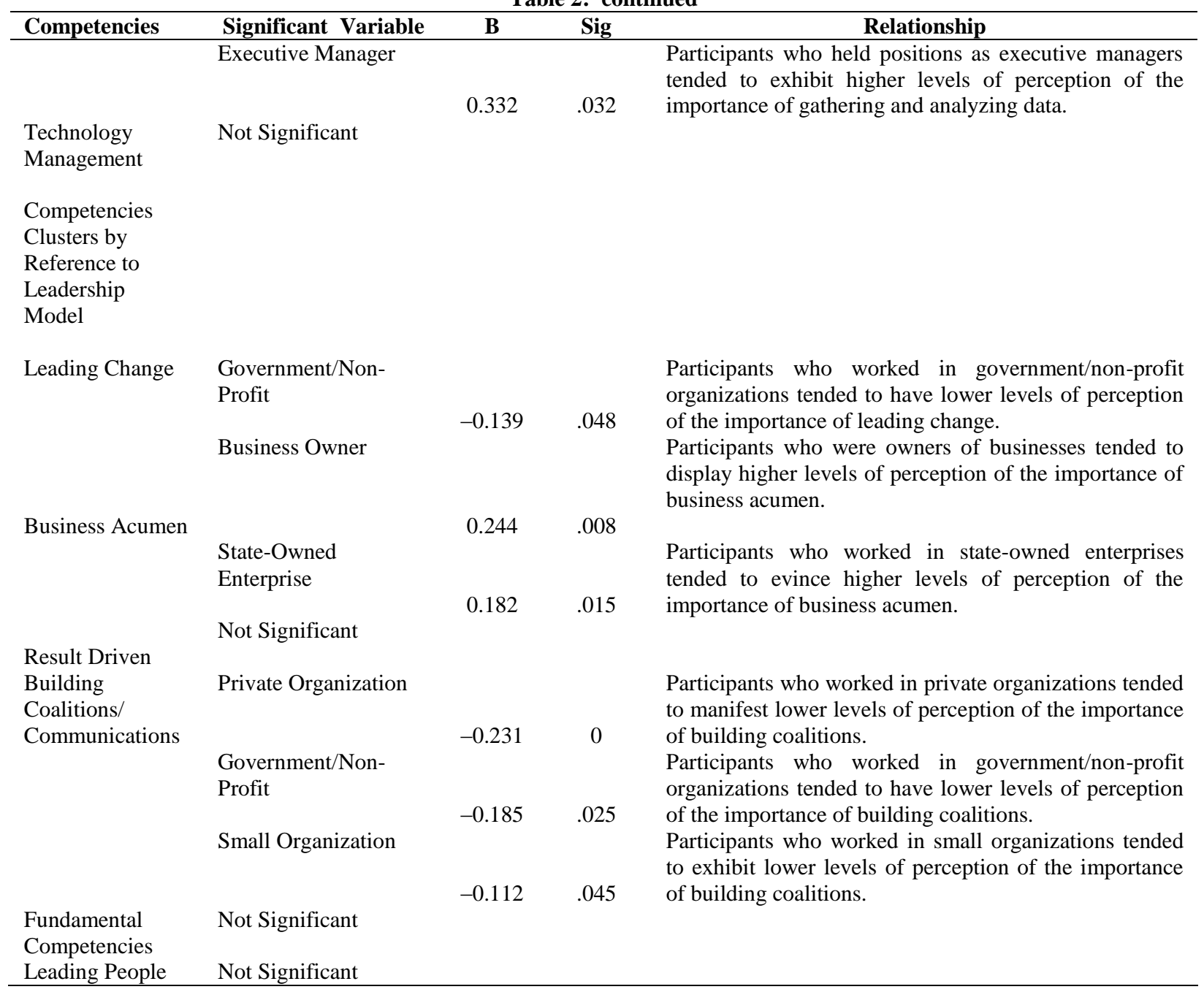

Research Question 3: What activities would be efficacious in developing leadership competencies in higher echelon to middle-level managers in Thailand?

Results of this investigation indicated that the five most efficacious activities that could be used to develop the leadership competencies of higher echelon to middle-level managers in Thailand on the basis of the perspectives of the participants are as follows:

1. Test, assessments or other measures of skills $(M=3.27)$;

2. Determining competency gaps when formulating guidelines for training and development programs $(\mathrm{M}=$ 3.24);

3. $\quad$ Coaching by internal mentors $(M=3.24)$;

4. External workshop training or seminars $(M=3.18)$; and

5. Role-playing or simulation training $(M=3.17)$. 


\section{CONCLUSION}

In drawing conclusions from the answer to the first research question, we learned that the most important competencies are honesty and integrity, accountability, team building, customer service, continual learning, vision, strategic thinking, and operational management. In respect to the second research question, we learned that there are statistically significant relationships between competencies and the demographical characteristics of the participants. Of the results presented in this study, we have seen in multiple contexts that participants who work in government/nonprofit organizations, multinational organizations and service businesses tended to evince lower levels of perception of strategic thinking. Of the participants who worked in supervisorial position, the tendency was exhibited to the effect that they had lower levels of perceptions of honesty and integrity and team building. Those working in service businesses tended to display lower levels of perception of the importance of continual learning, as we saw. All of this constitutes a critical situation because there is an absence of perception of the most important competencies.

Finally, the researcher was able to establish that the five most efficacious activities for developing leadership competencies for higher echelon to middle-level managers in Thailand were testing, assessments or other measures of skills and determining competency gaps such that guidelines can be formulated for closing these gaps in training, as well as instituting development programs, coaching by internal mentors, external workshop training or seminars, and role-playing or simulation training.

As has been frequently mentioned passim, the linkages between the answers to these three research questions can be beneficial to practitioners, academics and researchers, policy makers and managers, especially if they take full cognizance of the confluence of the nexus between leadership competencies and the demographical characteristics of the participants. Furthermore, taking full cognizance of the relationships between leadership competencies and demographical characteristics can lead to a profoundly fruitful influence on the development of efficacious programs for employee development. This would be a matter of vital concern and overarching interest, as we know, to researchers and professional practitioners in the field of management.

The theoretical implications of this study contribute to the knowledge base of competency inquiry by virtue of having filled gaps in the literature and by substantiating the findings of previous research. This study reveals that there are strong statistically significant relationships between leadership competencies and the demographical characteristics of those in leadership positions, as has been mentioned in various contexts in the course of this investigation.

The findings of this study contribute to the academic literature by providing support for fostering a compelling conceptual framework for competency studies in view of the paramount importance of developing leadership competencies for higher echelon and middle-level managers in Thailand. Not only are the findings of this study an important addition to the developing stream of literature related to the conceptual underpinnings of competency studies, but the findings are also important because they provide new information in a domain not previously investigated. Therefore, the findings of this study assist in the process of constructing a cogent framework for the close and empirically-informed conceptual analysis of the most salient relationships between leadership competencies and the demographical characteristics of business leaders.

\section{AUTHOR INFORMATION}

Associate Professor Niruemol Maneesawangwong earned her Bachelor of Business Administration at Ramkahmaheng Univeristy in 1974 and her Master of Business Administration at Chulalongkorn University in 1988. Currently, she is an Associate Professor of General Management at Ramkhamhaeng University, Thailand. E-mail: niruemol.advanced@gmail.com.

Dr. Auychai Suvanujasiri earned his MBA at The University of Findlay, Ohio, USA in 2002. He earned his Ph.D. international program at Ramkhamhaeng University in 2009. Currently, he is a lecturer of International Business at Ramkhamhaeng University, Thailand. E-mail: auychai@gmail.com. Corresponding author. 


\section{REFERENCES}

1. Boyatzis, R. E. (2008). Competencies in the 21st century. Journal of Management Development, 27(1), 512.

2. Eyde, L., Gregory, D., Muldrow, T., \& Mergen, P. (1999). High-performance leaders: A competency model. Washington, DC: Office of Personnel Management.

3. Hayes, J. (2007). Evaluating a leadership development program. Organization Development Journal, 25(4), 89-95.

4. Jackson, D., \& Humble, J. (1994). Middle managers: New purpose, new directions The Journal of Management Development, 13(3), 15-16.

5. $\quad$ Ling, W., Chia, R. C., \& Fang, L. (2000). Chinese implicit leadership theory. The Journal of Social Psychology, 140(6), 729-739.

6. McClelland, D. D. (1973). Testing for competence rather than for "intelligence". American Psychologist, 28(1), 1-14.

7. Qiao, J. X., \& Wang, W. (2009). Managerial competencies for middle managers: Some empirical findings from China. Journal of European Industrial Training, 33(1), 69-80.

8. Spencer, L., \& Spencer, S. (1993). Competence at work: Models for superior performance. New York: John Wiley \& Sons.

9. Vichita Vathanophas \& Jintawee Thai-ngam. (March, 2007) Competency requirements for effective job performance in the Thai public sector. Contemporary Management Research, 3(1), 45-70.

10. Wang, W. (2006). Middle manager leadership competencies in China: perceptions of MBA and EMBA students at Nankai University, the Pennsylvania State University, dissertation. 